\title{
Assessment of the fibre orientation factor in SFRC slabs
}

\author{
A. Blanco*, P. Pujadas, A. de la Fuente, S.H.P. Cavalaro, A. Aguado \\ Department of Construction Engineering, Universitat Politècnica de Catalunya, UPC, Jordi Girona 1-3, 08034 Barcelona, Spain
}

\section{A R T I C L E I N F O}

\section{Article history:}

Received 17 April 2014

Received in revised form 2 August 2014

Accepted 1 September 2014

Available online 21 September 2014

\section{Keywords:}

A. Fibres

B. Mechanical properties

C. Finite element analysis (FEA)

D. Mechanical testing

\begin{abstract}
A B S T R A C T
The design of steel fibre reinforced concrete (SFRC) structures is evolving towards a new approach that uses correction factors to consider differences between the small-scale characterisation specimens and the real-scale elements. Recently, the Model Code 2010 proposed an orientation factor $(K)$ that accounts for the effects of the orientation in the structural response of elements. The present study focuses on the identification of this factor in SFRC slabs with different dimensions. For that, flexural tests on real-scale slabs were conducted and the fibre orientation was assessed with an inductive method. A finite element analysis showed the differences between the experimental curves and the prediction of the Model Code without considering $K$. Based on the results obtained, a range of values is proposed for $K$ and validated. This study sheds light on possible modifications that this philosophy of design might require to better reproduce the behaviour of slabs.
\end{abstract}

(c) 2014 Elsevier Ltd. All rights reserved.

\section{Introduction}

Steel fibre reinforced concrete (SFRC) has arisen as an alternative to traditional reinforced concrete (RC) in structural applications that demand materials with tensile stress bearing capacity and ductility. Nevertheless, the fact that fibres are distributed in the mass leads to a behaviour different from that of RC. While in the latter steel rebars tend to be efficiently placed in the section with regard to the cracking plane, in SFRC the orientation of the fibres may not be as efficient. This has a direct effect on the postcracking tensile response, either enhancing or penalising it [1].

Originally, the research conducted by the scientific community focused on the development of constitutive models for the design as well as on the implementation of characterisation tests for the assessment of the performance of the material. Back then, the first codes and guidelines did not incorporate the fibre orientation explicitly in the design. However, more recently numerous studies in the literature reported the big influence of this parameter on the structural response of FRC [2-5], suggesting the need to use correction factors to account for the differences between the small-scale characterisation specimen and the real-scale element.

In this regard, the Model Code 2010 [6] proposed an orientation factor that affects the design serviceability and ultimate residual strengths when favourable or unfavourable fibre orientations are experimentally verified. Examples of advantageous preferential orientations caused by the geometry are slabs and plates. The

\footnotetext{
* Corresponding author. Tel.: +34 93401 7347; fax: +34 934011036.

E-mail address: ana.blanco@upc.edu (A. Blanco).
}

casting direction of these elements is usually perpendicular to their largest surface. Moreover, due to their low height to width ratio, the concrete poured presents mainly a horizontal movement on the formwork. Since the fibres tend to align perpendicularly to the cast direction and in the same plane of the concrete flow, the number of fibres crossing the failure plane increases. In line with that, a recent study by Blanco et al. [7] revealed an enhanced sectional response in this type of element as the width increases.

The orientation factor may vary for the same type of element depending on the several aspects that modify the fibre orientation (the fresh-state properties of the concrete after mixing, the production process, the type of fibre and the geometry of the formwork) [8-10,2]. Although this new philosophy represents a paramount step forward in the integration of fibre orientation in the design, no specific guidelines on the quantification of such orientation factor is proposed. This fact reveals the need for further studies about the orientation in different typologies of structures and about the structural response obtained [11].

Furthermore, several questions yet must be answered. For instance, how the orientation factor should be calculated? Should the dimensions of the structure be considered when determining the effect of a favourable fibre orientation? How does the fibre orientation in the slabs and the orientation factor change with the dimensions of the element? Is the use of the same orientation factor for all strain levels enough to reproduce the behaviour of real-scale elements or different orientation factors are required depending on the strain reached?

Considering the above, this paper focuses in the assessment of the orientation factor for SFRC slabs with different dimensions, 
maintaining constant other parameters such as casting procedure and type of SFRC. For that, flexural tests on real-scale slabs were performed and the fibre orientation was assessed. Furthermore, orientation factors are proposed for the design of the slabs tested and then validated with a finite element analysis (FEA). This study represents a contribution towards a more robust design of SFRC elements. It provides an example of deduction of orientation factors and sheds light on additional modifications that this philosophy of design requires to better reproduce the behaviour of slabs.

\section{Experimental program}

Few examples of tests on real-scale SFRC slabs with different width and subjected to condition similar to the found in practice may be found in the literature. Therefore, an experimental program was conducted with the aim of assessing the mechanical response observed and to estimate the fibre distribution in this type of elements. The following sections present a description of the experimental program.

\subsection{Specimens}

Slabs with $3.0 \mathrm{~m}$ of length, $0.2 \mathrm{~m}$ of thickness and widths of $1.5 \mathrm{~m}, 2.0 \mathrm{~m}$ or $3.0 \mathrm{~m}$ were tested. These sizes were selected to reproduce possible dimensions of SFRC suspended slabs that may be used in buildings. According to the notation adopted, the slabs were either small $(\mathrm{S})$, medium $(\mathrm{M})$ or large $(\mathrm{L})$ depending on their width $(1.5 \mathrm{~m}, 2.0 \mathrm{~m}$ or $3.0 \mathrm{~m}$, respectively). Two slabs were cast and characterised for each size, making a total of six slabs. The letter A or B was appended to the notation in order to identify the elements of each pair (e.g. S_A or L_B) (see Table 1).

\subsection{Materials and concrete mix}

The concrete mix used to cast the slabs contained $40 \mathrm{~kg} / \mathrm{m}^{3}$ of hooked-end steel fibres Dramix ${ }^{\circledR}$ RC80/50BN and was designed to obtain a high fluidity, in order to minimise the vibration required. Three batches with the same mix proportion were produced to cast all slabs in three different days due to limitation in the mould available. Table 2 summarises the details of the concrete mix used. The slabs $L \_A$ and $M \_A$ were cast with the first batch, the slabs $L \_B$ and M_B were produced with the second batch and, the slabs S_A and S_B were cast with the third batch.

The mix was poured from the centre of the formwork (see Fig. 1) in all cases to avoid introducing additional variables to the study. Once the pouring of the material was finished, the walls of the formwork were vibrated externally during approximately $20 \mathrm{~s}$ to ensure a uniform distribution of the concrete in the mould.

The average results at 28 days for the modulus of elasticity $\left(E_{c m}\right)$, compressive strength $\left(f_{c m}\right)$ and residual flexural strengths $\left(f_{R i}\right)$ are presented in Table 4 . These properties were obtained according with the standards UNE 83507:2004 [12], UNE 83316:1996 [13] and EN 14651:2005 [14], respectively. The results of $E_{c m}$ and $f_{c m}$ correspond to the average of three specimens; whereas the values of $f_{R i}$ were obtained with the average of six beams. Notice that for the third batch only three beams were

Table 1

Dimensions of the slabs.

\begin{tabular}{ll}
\hline Notation & Dimensions [m] \\
\hline S_A and S_B & $1.5 \times 3.0 \times 0.2$ \\
M_A and M_B & $2.0 \times 3.0 \times 0.2$ \\
L_A and L_B & $3.0 \times 3.0 \times 0.2$ \\
\hline
\end{tabular}

Table 2

Concrete mix.

\begin{tabular}{lll}
\hline Materials & Characteristics & Quantities $\left[\mathrm{kg} / \mathrm{m}^{3}\right]$ \\
\hline Gravel $(6 / 15 \mathrm{~mm})$ & Granite & 520 \\
Gravel $(2.5 / 6 \mathrm{~mm})$ & Granite & 400 \\
Sand $(0 / 3 \mathrm{~mm})$ & Granite & 510 \\
Cement & CEM I 52,5 R & 350 \\
Filler & Marble dust & 300 \\
Water & - & 178 \\
Superplasticizer & Adva $^{\circledR}$ Flow 400 & 12 \\
Fibres & Steel fibres & 40 \\
\hline
\end{tabular}

tested and one of them failed due to malfunctioning of the crack mouth opening displacement (CMOD) control device.

The scatter observed in the results is high but smaller than the $20 \%$ reported in the literature $[15,16]$. The comparison of the residual flexural tensile strengths show that the first and the second batches present almost identical average values, whereas the third batch exhibits lower values. Given that the concrete mix used is the same and the other tests (compressive strength and modulus of elasticity) provide similar results for all batches, the difference in the post-cracking performance of the third batch is attributed to the reduced number of specimens tested. Therefore, hereinafter it will be assumed that the performance of the third batch is equivalent to the others.

\subsection{Mechanical test setup and procedure}

The slabs were placed over steel trestles located at the borders, extending over the central half of the sides (see Fig. 2). This setup was chosen to obtain a hyperstatic support condition that allows an internal redistribution of forces and the contribution of fibres in more than one direction, like in suspended slabs. The load was applied at the center of the element by means of a piston connected with a servo-hydraulic jack. Neoprene sheets (200 $\times 200 \times 20 \mathrm{~mm}$ ) were placed between the piston and the top of the slab to ensure full contact with the loading surface. To limit the contact area and to guarantee a more uniform load transmission to the supports, neoprene sheets were also placed between the slab and the steel trestles. In this case, the layer of neoprene was $2 \mathrm{~cm}$ thick, $20 \mathrm{~cm}$ wide and $1.5,1$ or $0.75 \mathrm{~m}$ long depending on the length of the supported side.

The load applied $(P)$, the displacement of the piston and the deflection $(\delta)$ at different locations of the slab were measured throughout the test. The assessment of the deflections was performed with 14 magnetostrictive displacement transducers located at the axes of the element, at the supports and in two diagonally opposed corners to evaluate the expected raising of these points. Fig. 3 indicates the exact position of the displacement transducers on the top surface of the slabs. In the shortest direction the distance $a$ between the transducers was variable depending on the width of the slab, being $20 \mathrm{~cm}$ for slabs S, $32 \mathrm{~cm}$ for slabs M and $53 \mathrm{~cm}$ for slabs $\mathrm{L}$. The displacement transducers placed in the longest direction were separated $53 \mathrm{~cm}$ apart.

Notice that no transducer was placed at the centre of the slab since this position is occupied by the piston of the jack. Therefore, in order to assess the deflection at the centre, the measurements from the other transducers were used. The analysis of the data obtained during the test indicated that a linear relation $\left(R^{2}=0.999\right.$ in all cases $)$ exists between the displacement and the position of the transducer regarding the symmetry axes. Considering that, an extrapolation of a linear regression was used to estimate the expected movement at the centre of the slab. To derive the deflection, this movement should be corrected by subtracting the displacement from the neoprene layers at the 

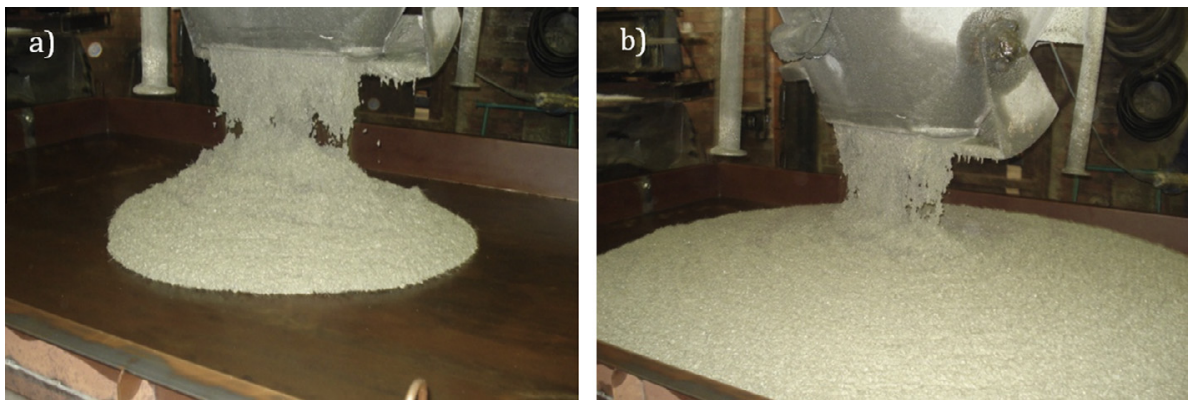

Fig. 1. (a) Concrete pouring in the centre of the slab and (b) flow of concrete to the edges.
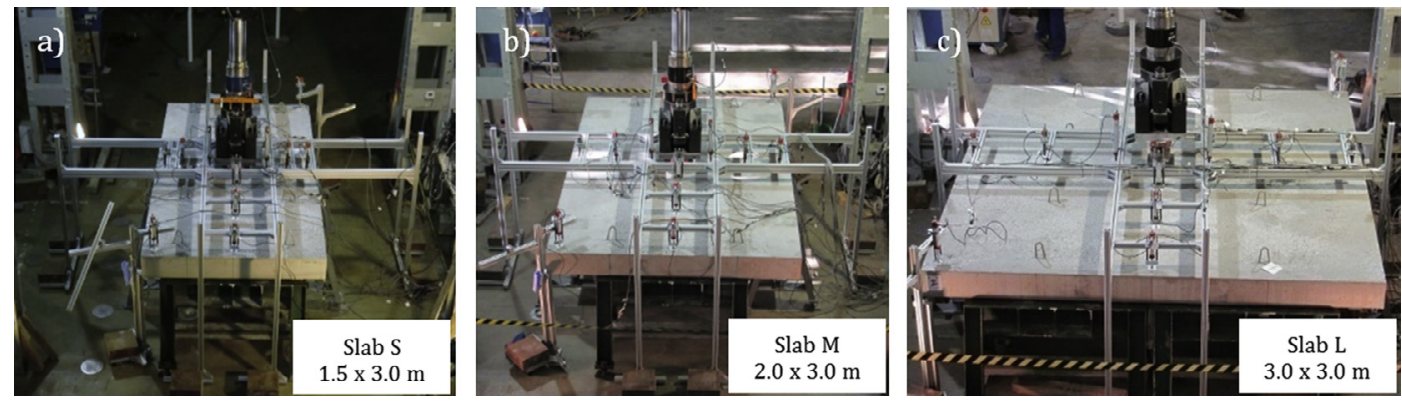

Fig. 2. Setup for slab (a) S, (b) M and (c) L.



Fig. 3. Location of the displacement transducers on the top surface of the slab.

supports (calculated as the average of the readings of transducers T1, T6, T12 and T7 shown in Fig. 3).

The tests were performed with displacement control of the jack, following a load procedure divided in two sequential stages. At the first stage, a smaller displacement rate was used to allow a clear appreciation of the arising and the propagation of cracks. Considering that the flexibility of the elements tested increases with the width, displacement rates of $0.15 \mathrm{~mm} / \mathrm{min}, 0.20 \mathrm{~mm} / \mathrm{min}$ and $0.25 \mathrm{~mm} / \mathrm{min}$ were adopted for slabs S, M and L, respectively. Once the extent of the major cracks had stabilized, the rate was increased to assess the behaviour of the slabs for high displacement values. Values of $0.20 \mathrm{~mm} / \mathrm{min}, 0.30 \mathrm{~mm} / \mathrm{min}$ and $0.40 \mathrm{~mm} /$ min were used in the second stage for slabs $\mathrm{S}, \mathrm{M}$ and $\mathrm{L}$, respectively. The slabs were loaded until the stabilization of the softening stage was observed and the rate of softening was approximately constant. As a general criterion, the tests were stopped once the post-peak load reached between $65 \%$ and $70 \%$ of the maximum load. This approach intended to provide the characterisation of the behaviour of the slabs for large deflection without approaching the collapse, which could compromise the posterior assessment of the crack pattern.

\subsection{Fibre distribution assessment}

The assessment of the fibre distribution in the slabs was conducted after the mechanical tests by means of a non-destructive magnetic method [17-19] applied on cubic specimens extracted from the elements. This method is based on the measurement of the alterations produced in a magnetic field when the SFRC specimen is placed within a coil. Such alterations are evaluated in the three main axes of the specimen. The summed measurements is related with the fibre content, whereas the differences among measurements indicate the alignment of the fibres in each direction. This method was already applied to real-scale structures to assess fibre content and fibre orientation [20-22].

To obtain specimens suitable for the test, cylindrical cores with $200 \mathrm{~mm}$ of height and $225 \mathrm{~mm}$ of diameter were drilled from the slabs (see Fig. 4a). Their location and orientation with regards to the sides of the slabs were properly marked before the extraction. The cylindrical cores were then cut into $150 \mathrm{~mm}$ cubic samples (see Fig. $4 \mathrm{~b}$ and c), keeping the resultant sides parallel to the sides of the slabs. First, the lateral edges of the cylinders were eliminated to obtain $150 \times 150 \times 200 \mathrm{~mm}$ prisms. Afterwards, the $25 \mathrm{~mm}$ thick slices at the top and bottom of the prism were cut.

The number of cores drilled ranged from 12 to 18 per slab, depending on the size of the element. The position of extraction was defined under the criterion of obtaining at least two samples close to each other, maximizing the area covered. Since the casting date for slabs S_A and S_B is the same and the load-deflection curves are very similar, only the former was characterised.

In order to assess the differences in terms of fibre distribution in the real-scale and small-scale elements, the beams used in the 



Fig. 4. (a) Detail of the core drilling, (b) cylindrical cores extracted, (c) cubic specimens and (d) cutting procedure.

bending tests were also characterised. The inductive method was applied in cubic specimens extracted as indicated in Fig. 5. Notice that the cut was performed at a distance of $75 \mathrm{~mm}$ from the edges to avoid the zone cracked during the bending test and to reduce the influence of the wall-effect close to the extremities of the mould.

The average fibre orientation in a certain direction $(i)$ is evaluated through the orientation number $\left(\eta_{i}\right)$. This parameter corresponds to the average projected length of all fibres along direction $i$, divided by the total fibre length. As a result, the values of $\eta_{i}$ may range from 0 (when fibres are parallel to the direction $i$ ) to 1 (when fibres are perpendicular to the direction $i$ ). This parameter is also related with the mechanical performance at a sectional level in case a crack appears perpendicularly to $i$. It is expected that the efficiency of the fibres and the post-cracking response would reduce as $\eta_{i}$ approaches 0 . On the contrary, the efficiency and the response would increase as $\eta_{i}$ approaches 1 .

For the cubic specimens tested with the magnetic method, the orientation number in the three main axes $(X, Y$ and $Z$ ) may be obtained through Eq. (1) proposed by Cavalaro et al. [19]. This equation considers the inductance measurements taken in the corresponding axis $\left(\Delta L_{i}\right)$, the sum of the measurements in the three axes $(\Delta L)$ and a coefficient $(\gamma)$ that accounts for the aspect ratio of the fibre.

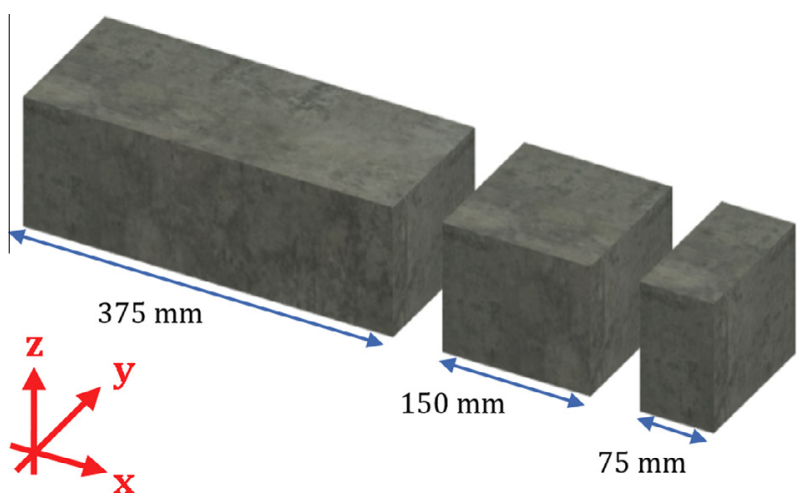

Fig. 5. Cutting procedure to obtain cubic specimens from the beams.
According with the formulation proposed by the same authors, the contribution of the fibres $\left(C_{i}\right)$ was calculated with Eq. (2) as the proportion of the summed orientation numbers observed in each axis. It is important to remark that the coordinated system adopted in the slabs has $X$ and $Y$ axes within the plane of the element, whereas in the beams $X$ is parallel to the length. In all of them, the $Z$ axis coincides with the casting direction.

$$
\begin{aligned}
& \eta_{i}=1.03 \cdot \sqrt{\frac{\Delta L_{i} \cdot(1+2 \cdot \gamma)-\Delta L \cdot \gamma}{\Delta L \cdot(1-\gamma)}}-0.1 \text { for } i=X, Y, Z \\
& C_{i}=\frac{\eta_{i}}{\eta_{X}+\eta_{Y}+\eta_{Z}} \quad \text { for } i=X, Y, Z
\end{aligned}
$$

In a perfectly isotropic SFRC, the $\eta_{i}$ measured with the inductive method in the three main axes tend to 0.5 . On the other hand, studies performed by Torrents et al. [18] and Galeote [23] in cores extracted from the central part of beams used in the flexural tests suggest an anisotropic fibre distribution with an orientation number close to 0.6 in the direction parallel to the axis of the beam and values between 0.3 and 0.4 in the other orthogonal directions.

It is important to remark that, when the experimental program was performed, the inductive method proposed by Torrents et al. [18] was capable of assessing the fibre orientation only in the three axes parallel to the sides of the cubic cores. Therefore, a general criterion was established for the extraction of the cores from the slabs and the small-scale beams. Since the formwork plays an important role in the fibre distribution, it was decided that in all cases the cubic cores would have the sides parallel to the formwork. This would provide a clearer picture of the influence of the formwork and simplify the definition of a fibre distribution pattern.

Despite the advantages of this criterion, it also has drawbacks. In case the cracks in the slabs are not parallel to the sides of the formwork, the orientation measured would not necessarily correspond to that found perpendicular to the cracks. Consequently, any intent to justify the differences in terms of the structural response based on the orientation number would require a conversion of the orientation measured parallel to the formwork to that expected perpendicularly to the cracks. For that, a simplified approach was proposed and applied, as described in Section 5. 


\section{Results and discussion}

\subsection{Crack patterns}

Fig. 6 shows the crack pattern observed after testing the slabs. In general, main cracks (thicker black lines) and secondary cracks (thinner grey lines) are observed. The former are the first to be observed during the test, marking a change in the stiffness of the element. They usually extended from the point of load application to the end of the supports, presenting openings several times bigger than those of the secondary cracks. This is consistent with the yield line theory and the experimental results from the literature [24].

The secondary cracks became visible as a result of an internal redistribution of stresses once bigger displacements were applied. An increase in the number of secondary cracks is observed as the width increases. In other words, the redistribution capacity increased with the width. It is also important to remark that the bigger number of main cracks observed in the slabs $\mathrm{M} \_\mathrm{B}$ and $\mathrm{L} \_\mathrm{B}$ suggest that they are more like to exhibit a post-cracking behaviour different from their corresponding pairs (M_A and $L \_A$ ).

\subsection{Load-deflection $(P-\delta)$ curves}

Fig. 7 shows the experimental results in terms of the vertical load versus the deflection estimated at the centre of the slabs. A considerable difference in the structural response of slabs $\mathrm{S}, \mathrm{M}$ and $\mathrm{L}$ was expected due to variation in the size of the elements. However, the average maximum loads for slabs S, M and $\mathrm{L}$ are $335.5 \mathrm{kN} 313.5 \mathrm{kN}$ and $288.6 \mathrm{kN}$, respectively. The maximum load exhibited by the slabs $\mathrm{S}$ is $16.3 \%$ higher than the average of slabs $\mathrm{L}$, even though the width of slabs $\mathrm{L}$ is $100 \%$ bigger than that of slabs $\mathrm{S}$. These results suggest that the fibre reinforcement allowed the larger slabs ( $\mathrm{M}$ and $\mathrm{L}$ ) to reach load levels close to those of the slabs $\mathrm{S}$, despite the increase in the width. It is evident that the bearing capacity of the steel fibres as the only reinforcement compensates for the influence of the geometry, providing a ductile behaviour and reducing the differences regarding the maximum load reached during the test.

Another parameter that indicates the structural contribution of the fibres and the ductile behaviour of SFRC is the high residual load in comparison with the maximum load reached during the test. In the case of the slab $\mathrm{L} \_\mathrm{A}$ the residual load is $217.7 \mathrm{kN}$ for the maximum deflection reached $(68.2 \mathrm{~mm})$ whereas the slab L_B presents a residual load equal to $184.5 \mathrm{kN}$ for the maximum deflection reached $(47.8 \mathrm{~mm})$. These values correspond to $73 \%$ and $66 \%$ of the highest load measured for each of them.

The curves also reveal that the pairs of slabs present a similar behaviour for small deflections. However, the differences grow with the deflection and the level of damage produced. For example, the values measured in the slabs $\mathrm{L}$ for $1 \mathrm{~mm}$ only differ by $0.7 \%$;
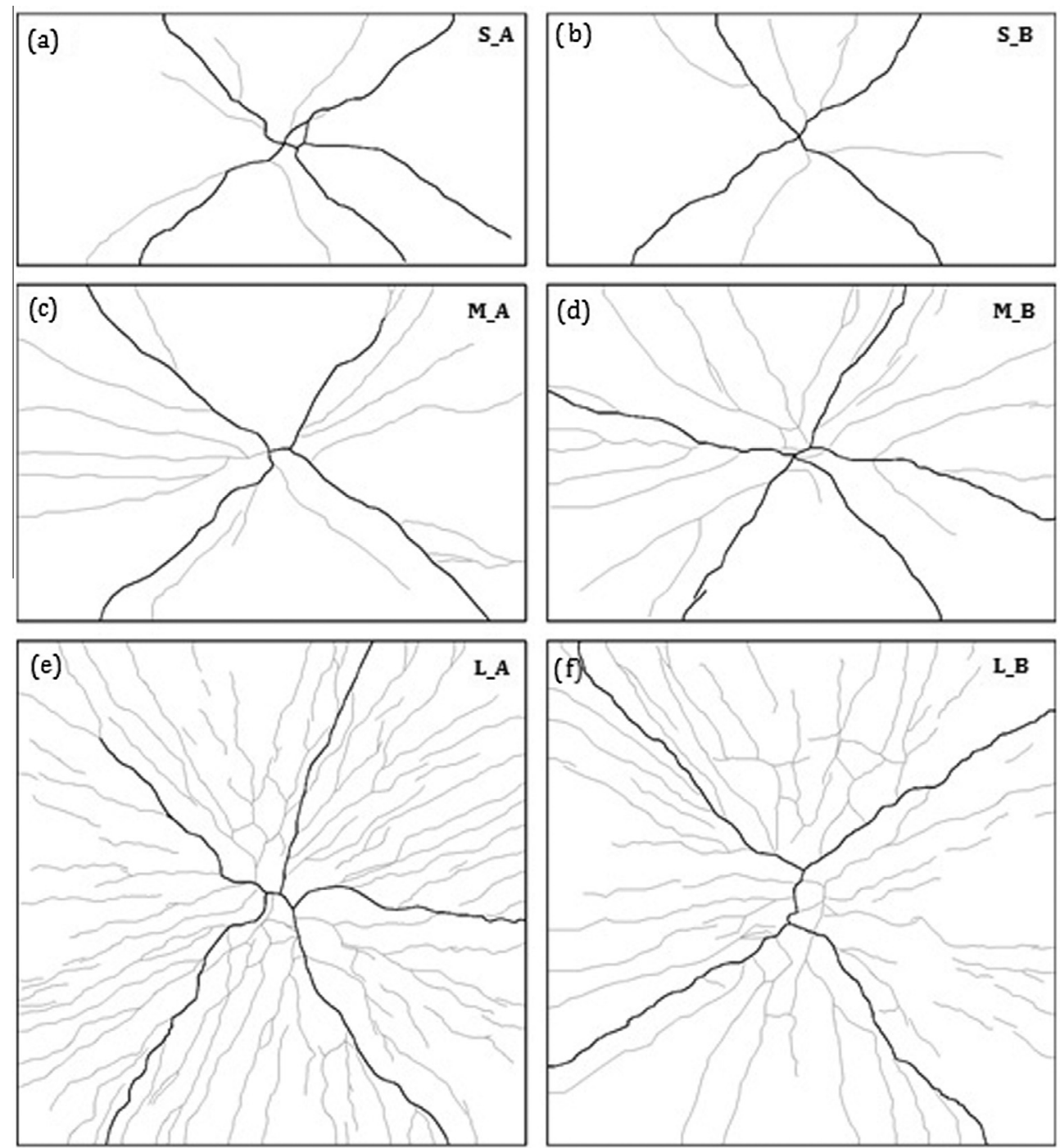

Fig. 6. Detailed crack patterns of slabs (a) $S \_A$; (b) $S \_B$; (c) $M \_A$; (d) $M \_B$; (e) L_A and (f) L_B. 

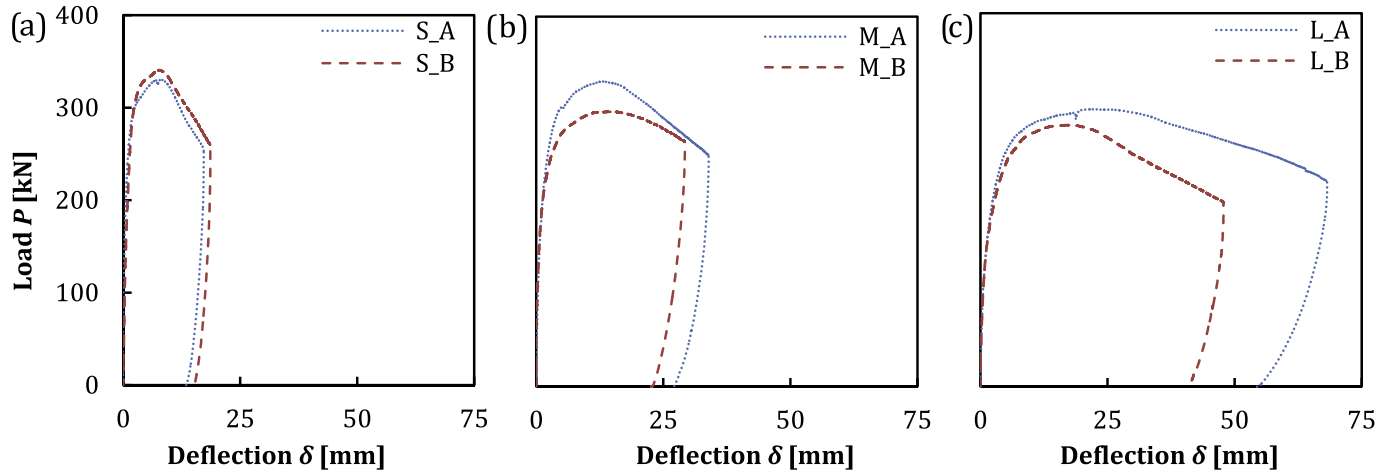

Fig. 7. $P-\delta$ curves for slabs: (a) S, (b) M and (c) L.

whereas for $20 \mathrm{~mm}$ and $40 \mathrm{~mm}$ the difference increases up to $6.5 \%$ and $25.7 \%$, respectively. The reason for the increasing difference in load values with large deflections may be the fibre reinforcement itself. Before cracking occurs, the response of the slabs of each pair is almost identical since their performance and the first cracking appearance depend on the concrete matrix properties. Nevertheless, after the first crack appears, the development of new cracks depends on the distribution and orientation of the fibres in the concrete matrix. This means that dispersions will lead to the development of different crack patterns, ultimately producing a variation of the structural response. As mentioned in Section 3.1, this is more evident for the pair of slabs $M$ and $L$ that present either 4 or 5 main cracks. On the contrary, the pair of slabs $S$ has similar behaviour justified by almost the same crack pattern.

\subsection{Fibre distribution}

The results of the inductive method for the fibre distribution are presented in Fig. 10 in a map with the location of each specimen in the slab. The circumscribed number shows the reference used to identify the cores. The fibre distribution is represented through the orientation number in parenthesis and the contribution of the fibres in percentage (blue values were obtained along $X$ axis and red along $Y$ axis). Notice that the remaining percentage to complete $100 \%$ equals the proportion of fibres placed along the $Z$ axis.

The results suggest a preferential orientation perpendicular to the casting direction ( $Z$ axis), as expected due to the geometry of the element and the casting procedure. Furthermore, other preferential orientations are detected near the walls of the slab where the fibres are aligned parallel to the boundaries (see specimens located near the edges in all of the slabs of Fig. 8). Such outcome is the result of the wall-effect of the formwork [25-27].

As a general trend, specimens located near the centre of the slab present similar orientations in both axes. The fibre orientation changes at increasing distance from the casting point (see specimens 6, 5, 4 and 2 of slab S_B in Fig. 8a). The cause of this result is related with the extensional or radial flow of concrete, illustrated in Fig. 9. According to the latter, the velocity profile exerted by the movement of concrete generates forces that cause the fibres to drift, rotate and align perpendicular to the direction of the flow. Consequently, they tend to change their orientation while moving from the pouring point (at the centre of the slab) towards the edges of the slab, as shown in Fig. 9. This becomes more evident as the flow distance covered by the SFRC increases. Such observation is consistent with the experimental results obtained here and with other from the literature in which the flow is governed by extensional stresses $[8,28,4]$.

Due to the combination of the wall-effect and the extensional flow, three main zones of orientation may be defined in each slab according to Fig. 10. In the central zone, a similar alignment of fibres may be assumed in both axes, whereas a tendency of preferential orientation parallel to the edges is observed in the most external zone. The intermediate zone marks a change between both conditions. In the random slab of Fig. 10, a characteristic orientation is indicated by a range of values corresponding to the fibre alignment measured in the experimental program. The range is defined by the second quartile (the lowest value) and the 95th percentile (the highest value) of the results of the specimens from all slabs located in the same zone.

Notice that the length of the external zone is the average of the distances containing the cores from the edge (usually between 32 and $36 \mathrm{~cm}$ ). In the central zone a double condition depending on the length $L_{1}$ (where $L_{1} \leqslant L_{2}$ ) of the slab is considered. This double condition takes into account that in a narrow slab the distance covered by the concrete flow is shorter in one direction. In such case, the concrete flow would reach the edges in one direction much earlier than in the other direction, raising the level of the concrete and affecting the upcoming concrete flow. This creates a new border acting as a wall that would change the orientation of the fibres, thus reducing the extent of the central zone. Therefore, the length of the central zone is the minimum value between $0.3 \cdot L_{1}$ and $60 \mathrm{~cm}$. On the right side of Fig. 10, an illustrative representation of the alignment along the $X$ axis in a cross section is depicted. This evolution corresponds to the tendency of the fibres to orientate perpendicular to the flow of concrete as they advance from the centre to the edges.

Notice that the proposed division of the slabs in zones responds to the analysis of the results obtained for a certain casting procedure and a limited number of geometries studied. The annotation of the zones proposed could be improved by further research on different geometries. Moreover, the pattern described may change if other casing procedures were performed.

The average orientation numbers $\left(\eta_{i}\right)$ in the three directions $X, Y$ and $Z$ are presented in Table 4 for the slabs and the beams used in the bending test. For the slabs, the average of the results in each zone indicated in Fig. 10 was performed. This procedure intends to avoid that a zone in which more cores were extracted would affect the average more than zones with a smaller number of extracted cores. In the case of the beams, the average of 12 cubic specimens cut from 6 beams was considered.

As observed in previous works from the literature, the smallest orientation number are obtained along the casting direction $(Z$ axis). This may be attributed to the flow of concrete during the filling of the moulds and the effect of vibration applied that tend to align the fibres in the horizontal plane. For the beams, the highest orientation number is obtained along the length ( $X$ axis) probably because of the clear flow restrictions and the marked influence of the wall-effect in this case. Smaller values are obtained in all slabs since an extensional flow is evident and the wall-effect from the 

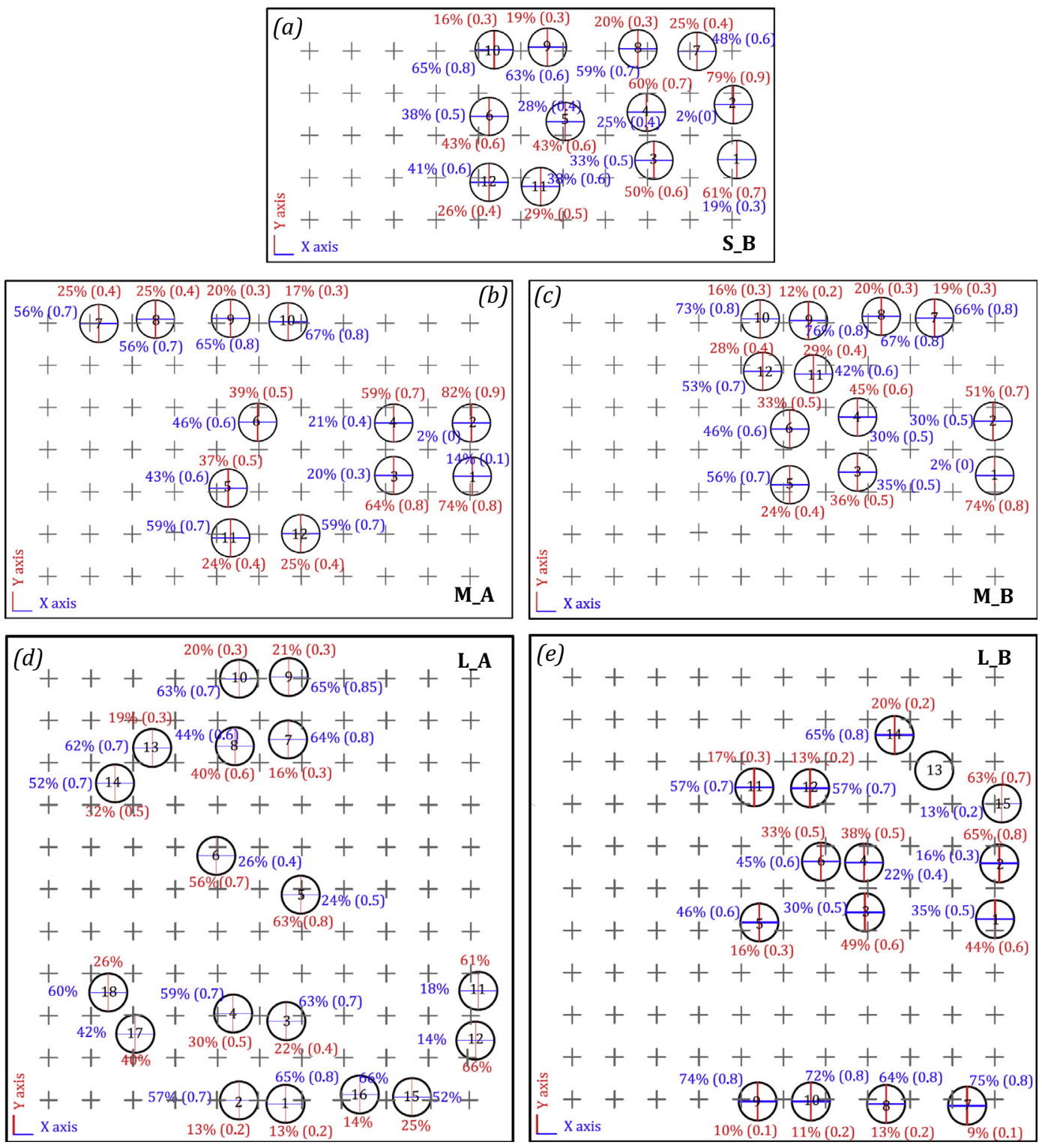

Fig. 8. Fibre orientation in specimens of slabs: (a) $S \_B$, (b) $M \_A,(c) M \_B$, (d) $L \_A$ and (e) $L \_B$.

Formwork

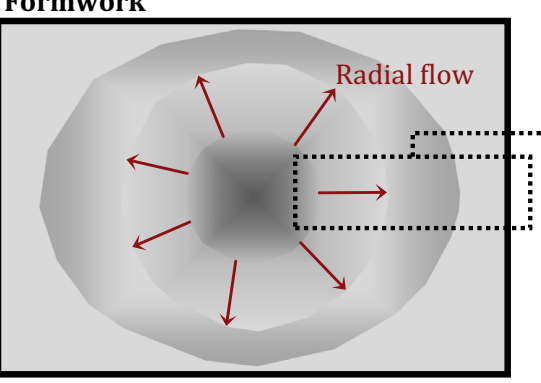

Fig. 9. Rotation of fibres while moving from the centre of the slabs to the edges. lateral of the moulds influences a more reduced proportion of the element.

Although Table 4 provides a general view of the fibre distribution, the expected repercussion in the structural response is not so clear in the case of the slabs. In fact, none of the axes used for

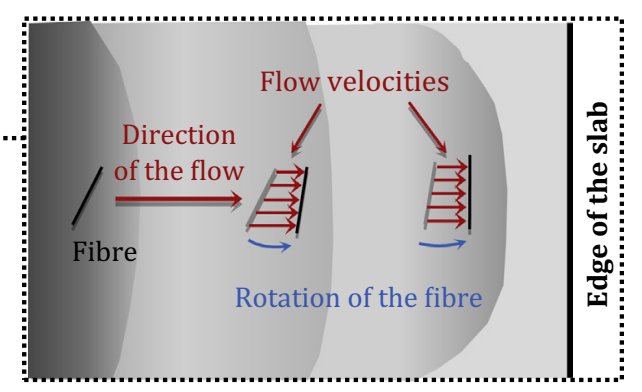






Fig. 10. Division of slabs in zones depending on fibre orientation.

the structural response, it would be interesting to estimate the orientation number in the axis perpendicular to the cracks of the slabs.

Given that such estimation is not mathematically feasible with the results of only three orthogonal axes; a simplified approach was used to derive a fair comparison between the fibre distribution in the beams and in the slabs regarding the cracked plane. The maximum angle $(\theta)$ formed between the resulting vector of the orientation number and the direction perpendicular to the crack is estimated. Table 4 shows the results obtained considering that the average angle of the cracks with the $X$ axis is $60^{\circ}, 57^{\circ}$ and $55^{\circ}$ for slabs $\mathrm{S}, \mathrm{L}$ and $\mathrm{M}$, respectively. Notice that the angle formed is twice as big in the slabs in comparison with the beam. This indicates that fibres would tend to be more efficiently aligned in the latter than in the former. Consequently, an overestimation of the experimental mechanical response of the slabs would be expected if the constitutive equations obtained from the bending test were used in numerical models.

\section{Numerical simulation}

\subsection{Description of the FEM model}

A numerical simulation of the structural behaviour was performed and compared with the experimental results in order to evaluate the possible overestimation indicated in the previous section. The numerical simulation was conducted in the finite element software ATENA 4.3.1g [29], which includes specific material models for concrete and elements for a 3D analysis. This was essential in the present study since redistribution of moments and the contribution of fibres in more than one direction occur during the test.

The tensile behaviour of concrete was simulated with non-linear fracture model combined with the crack band method and the smeared crack approach. In tension, the constitutive model included in the Model Code 2010 [6] was selected. Notice that in this case the orientation factor $K$ was considered 1.0 so that no effect of differential orientation was taken into account. In other words, it is assumed that the sectional responses of the slabs and of the specimen characterised in the bending test are equivalent.

The maximum crack opening is related with the ultimate strain $\left(\varepsilon_{u}\right)$ considered in the constitutive model. The limitation of the contribution of the fibres was implemented in accordance with the recommendations from the Model Code 2010. Consequently, a stress of 0 is resisted once the strain surpasses $\varepsilon_{u}$. Notice that a maximum $\varepsilon_{u}$ of $20 \%$ is also established for elements subjected to bending. Therefore, in case the formulation from the Model Code 2010 provided a value for $\varepsilon_{u}$ bigger than this limit, the constitutive curve was considered only up to a strain of $20 \%$. Hence, the part of the curve that corresponds to higher strain levels was neglected and a remaining residual strength of 0 was assumed.

The crack band size was automatically calculated by ATENA and the characteristic size used to estimate the strain was defined according with other works from the literature. According to de Montaignac et al. [30] the recommended values of the characteristic length $\left(l_{c}\right)$ to simulate the structural performance of SFRC without traditional reinforcement vary from half the height $(h / 2)$ to twice the height $(2 h)$ of the element simulated. Considering this, the influence of $l_{c}$ on the results of the FEM was analysed prior to selecting one for subsequent analyses. Such values are $100 \mathrm{~mm}$ and $200 \mathrm{~mm}$, which correspond respectively to half the full height $(h / 2)$ and the height $(h)$ of the slabs tested. The $P-\delta$ curves obtained with both characteristic sizes for the models of slabs $\mathrm{S}$ and $\mathrm{L}$ are shown in Fig. 11.

The results reveal that the influence of the selected values of $l_{c}$ on the $P-\delta$ curves is almost negligible. Such outcome was previously reported by Kooiman [31] that observed a small sensitivity of the load-bearing capacity of SFRC to the values of $l_{c}$, particularly for high deflections. Based on the results obtained and the findings of previous studies from the literature [31,32], the value of $l_{c}$ equal to $h / 2(100 \mathrm{~mm})$ was considered for the present study.

The neoprene sheets placed at the loading point and at the support were simulated using the properties obtained experimentally in the tests of the EN 1337-3:2005 [33]. A linear elastic regime according with Hooke's law was assumed due to the small values of compressions and strains reached at the supports during the simulations. In addition, the friction between the slab and the support and the mixed stress state produced as a result of it were also simulated. Simply supported conditions were imposed by restraining the vertical displacement of the bottom face of the neoprene located in the supports. The load case consisted of a vertical displacement acting simultaneously at all nodes on the top face of the neoprene in contact with the piston.

Table 5 shows the material properties of the SFRC, the neoprene and the interface elements used. Notice that the modulus of elasticity and the compressive strength of the SFRC correspond to the results obtained in the experimental program shown in Table 3.

The finite element mesh was composed by tetrahedral solid elements. The size of the mesh was defined with the aim of assuring the accurate reproduction of the localised cracking of SFRC without compromising the calculation time since several models would be processed to obtain the constitutive equation that best fits the experimental results. For that reason, the possibility of simulating a reduced model with only one quarter of the slabs was assessed. The preliminary analysis showed that the $P-\delta$ curves for the complete slab and for the quarter of the slab are practically identical. 

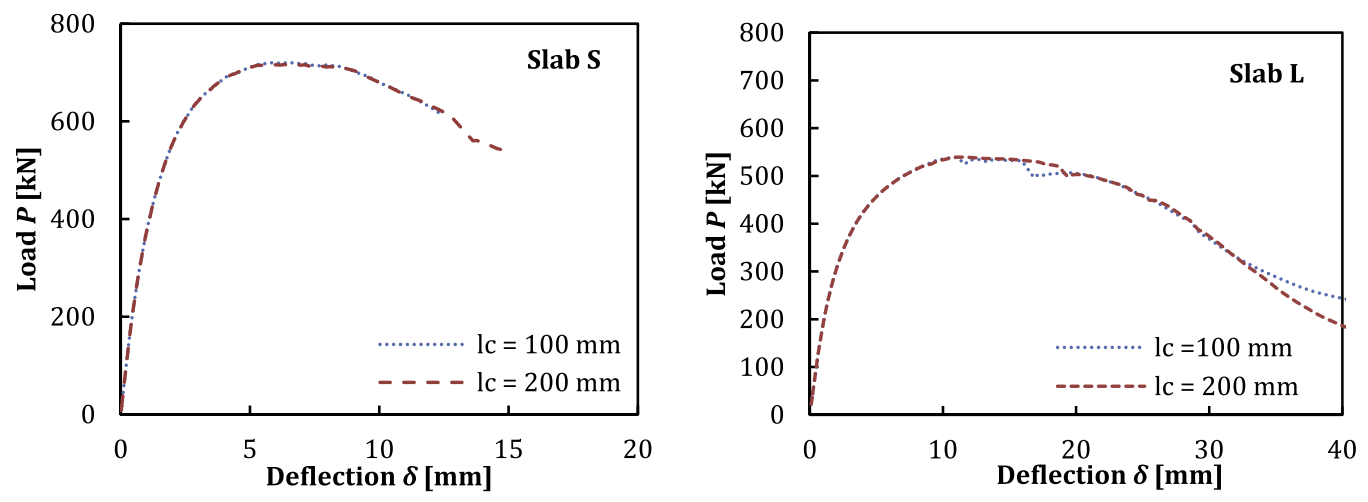

Fig. 11. Influence of the lc on the $P-\delta$ curves provided by the model: (a) slab S and (b) slab L.

Table 3

Modulus of elasticity, compressive strength and residual flexural strengths at 28 days.

\begin{tabular}{|c|c|c|c|c|c|c|c|}
\hline \multirow[t]{2}{*}{ Property } & & \multicolumn{2}{|l|}{ First batch } & \multicolumn{2}{|l|}{ Second batch } & \multicolumn{2}{|l|}{ Third batch } \\
\hline & & Average [MPa] & $\mathrm{CV}[\%]$ & Average [MPa] & $\mathrm{CV}[\%]$ & Average [MPa] & $\mathrm{CV}[\%]$ \\
\hline Modulus of elasticity & $E_{c m}$ & 29,030 & 0.96 & 28,640 & 2.79 & 30,160 & 2.20 \\
\hline Compressive strength & $f_{c m}$ & 46.73 & 0.77 & 49.46 & 0.59 & 46.77 & 2.54 \\
\hline \multirow[t]{5}{*}{ Residual flexural strengths } & $f_{L}$ & 5.42 & 7.05 & 5.29 & 2.23 & 3.76 & 7.96 \\
\hline & $f_{R 1}$ & 6.25 & 12.50 & 6.13 & 13.71 & 3.75 & 22.29 \\
\hline & $f_{R 2}$ & 7.02 & 12.39 & 7.04 & 15.77 & 4.24 & 17.91 \\
\hline & $f_{R 3}$ & 7.05 & 11.59 & 7.08 & 15.05 & 4.30 & 15.88 \\
\hline & $f_{R 4}$ & 6.62 & 12.08 & 6.62 & 12.08 & 4.17 & 15.68 \\
\hline
\end{tabular}

Based on such outcome [7], the reduced model was selected. Notice that the displacement perpendicular to the symmetry planes was also restrained.

\subsection{Results}

Fig. 12 shows the $P-\delta$ curves estimated with the constitutive equation from the Model Code 2010 (for $K=1.0$ ) and the experimental results. The general tendency observed is a significant overestimation of the experimental curves, which becomes more evident as the width of the element diminishes. For instance, the maximum load measured during the test of slabs $\mathrm{L}$ and $\mathrm{S}$ represent $53 \%$ and $46 \%$ of the estimated response, respectively. The results reveal that the direct application of the constitutive model obtained from the flexural tests of small beams to the design of SFRC slabs under the assumption that the fibre orientation is the same in both elements may lead to unsafe predictions of the structural response. This confirms the hypothesis presented in Section 3 based on the results of the inductive method.

Such outcome reinforces the need for correction factors that take into account differences between the small-scale specimen and the real-scale element. Therefore, according with the design philosophy proposed in the Model Code 2010, the orientation factor $(K)$ is assessed for the case of the slabs tested.

\section{Orientation factor for SFRC slabs}

Following the philosophy of the Model Code 2010 to account for the fibre orientation, the values of $\sigma_{2}$ and $\sigma_{3}$ from the bending test were divided by $K$. Therefore, the constitutive equation is obtained by applying this procedure to the values presented in Table 5 . The modified constitutive equation was then used in the finite element simulations.
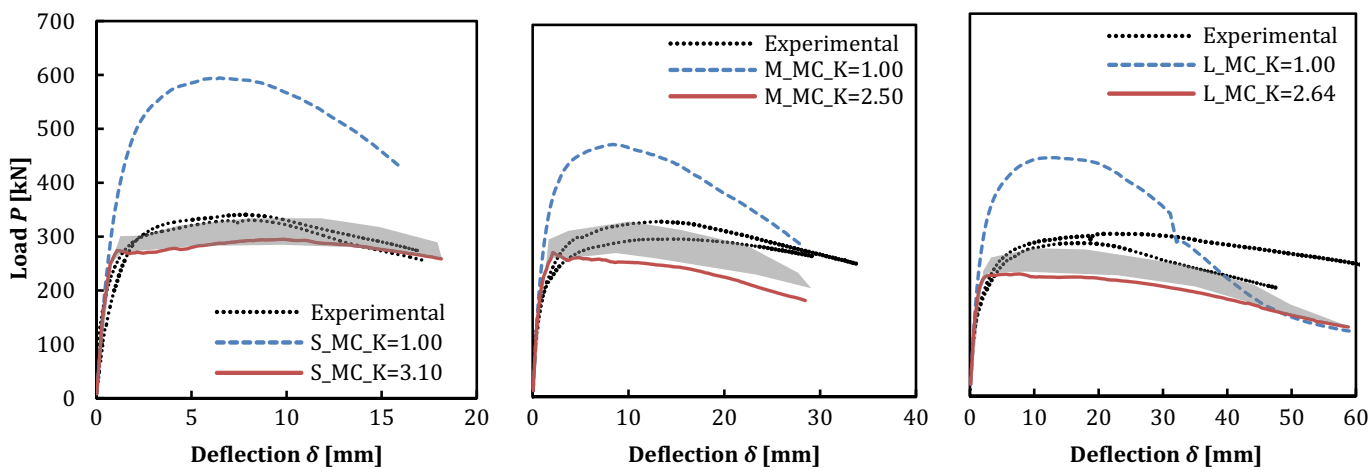

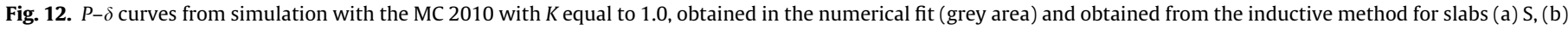
$\mathrm{M}$ and (c) L. 
Table 4

Average orientation numbers of the beams and the slabs.

\begin{tabular}{lllll}
\hline Element & \multicolumn{3}{l}{ Orientation number } & \multirow{2}{l}{$\begin{array}{c}\text { Maximum angle with direction } \\
\perp \text { to crack }(\theta)\left[^{\circ}\right]\end{array}$} \\
\cline { 2 - 4 } & $\eta_{x}$ & $\eta_{y}$ & $\eta_{z}$ & \\
\hline Beams & 0.67 & 0.45 & 0.31 & 39.3 \\
Slabs S & 0.54 & 0.52 & 0.37 & 75.5 \\
Slabs M & 0.62 & 0.48 & 0.31 & 72.0 \\
Slabs L & 0.60 & 0.44 & 0.34 & 73.0 \\
\hline
\end{tabular}

In the present study, the orientation factors that best fit the experimental results were assessed following two different approaches. In the first of them, the ranges of $K$ were determined through an iterative fitting procedure. In the second of them, a value was proposed for $K$ based on the results of the inductive method. For that, the angle between the resultant of the inductive method and the direction perpendicular to the cracks shown in Table 4 for the beam ( $\left.\theta_{\text {beam }}\right)$ and for the slabs $\left(\theta_{S}, \theta_{M}, \theta_{L}\right)$ were used. The orientation factor for each slab was calculated through Eq. (3), which considers that the mechanical response of the fibre is proportional to the cosine of the angle formed [34].

$K_{i}=\frac{\cos \left(\theta_{\text {beam }}\right)}{\cos \left(\theta_{i}\right)} \quad$ for $i=\mathrm{S}, \mathrm{M}, \mathrm{L}$

Table 6 summarises the range of values obtained for $K$ through both approaches. Almost all values are above 2, thus indicating that a severe reduction of $\sigma_{2}$ and $\sigma_{3}$ is required due to the differences in the fibre distribution. In this regard, it should be remarked that this unfavourable effect does not refer to the orientation of the fibres in the slabs alone, but rather to the differences in orientation between the beams and the slabs. In other words, the fibres in the beam are strongly aligned in the perpendicular direction to the cracking surface, exhibiting a more effective orientation than in the slabs.
Table 6

Average orientation factors of the slabs.

\begin{tabular}{lll}
\hline Slabs & Orientation factor $(K)$ & \\
\cline { 2 - 3 } & Inductive method & Iterative fit \\
\hline S & 3.10 & $2.50-3.20$ \\
M & 2.51 & $1.80-2.30$ \\
L & 2.64 & $1.90-2.40$ \\
\hline
\end{tabular}

Hence, the common assumption made in most design codes and recommendations of an equivalent orientation $(K=1.0)$ results in an unsafe predictions.

Table 6 also shows that the $K$ obtained using the inductive method is close to the range estimated through the iterative fit providing estimations that are slightly on the safe side. This suggests that the assessment of the fibre distributions might serve as a reference for the estimation of the orientation factor. The same conclusion may be obtained if the $P-\delta$ curves estimated with the finite element model are compared (see Fig. 12, in which the grey area indicates the range of curves obtained with the iterative fit). As expected, the shape of the curve and the absolute values reached are closer to the experimental results. Despite that, in general, the goodness of the fit decreases for large displacements. This was observed interchangeably throughout the numerical analysis since a good fit achieved for one part of the curve led to a fit slightly worst in the other part.

Such outcome suggests another relevant issue that may affect the general design philosophy proposed in the Model Code 2010. The curves of Fig. 12 reveal that applying the same $K$ for $\sigma_{2}$ and $\sigma_{3}$ may not allow a precise reproduction of the experimental curves. To achieve this, it might be necessary to define different values of $K$ for $\sigma_{2}$ and $\sigma_{3}$ or even to modify other parameters of the constitutive curve.

Table 5

Properties of the material defined in the models.

\begin{tabular}{|c|c|c|c|c|}
\hline Model & Model part & Material properties & Value & Reference \\
\hline \multirow{9}{*}{ Common properties for all models } & \multirow{2}{*}{ Neoprene sheets } & Average modulus of elasticity [MPa] & 35.00 & EN 1337-3:2005 \\
\hline & & Poisson ratio $[-]$ & 0.30 & EN 1337-3:2005 \\
\hline & \multirow[t]{5}{*}{ Interface material } & Normal stiffness $\left[\mathrm{MN} / \mathrm{m}^{3}\right]$ & $2.00 \cdot 10^{8}$ & - \\
\hline & & Tangential stiffness $\left[\mathrm{MN} / \mathrm{m}^{3}\right]$ & $2.00 \cdot 10^{8}$ & - \\
\hline & & Cohesion [MPa] & 1.00 & - \\
\hline & & Friction coefficient & 0.10 & - \\
\hline & & Cut-off traction stress [MPa] & 0.30 & - \\
\hline & \multirow[t]{2}{*}{ SFRC slab } & Poisson ratio $[-]$ & 0.20 & Eurocode 2 \\
\hline & & Tension characteristic size $[\mathrm{m}]$ & 0.10 & Pederson 1996, Kooiman 2000, etc. \\
\hline \multirow[t]{10}{*}{ Model S } & \multirow[t]{10}{*}{ SFRC slab } & Average compressive strength [MPa] & 46.80 & UNE 83507:2004 \\
\hline & & Average modulus of elasticity [GPa] & 30.60 & UNE 83316:1996 \\
\hline & & Average stress $\sigma_{0}[\mathrm{MPa}]$ & 3.09 & Model Code 2010 \\
\hline & & Average tensile stress $\sigma_{1}$ [MPa] & 3.44 & Model Code 2010 \\
\hline & & Average residual stress $\sigma_{2}[\mathrm{MPa}]$ & 2.44 & Model Code 2010 \\
\hline & & Average residual stress $\sigma_{3}$ [MPa] & 2.44 & Model Code 2010 \\
\hline & & Average strain $\varepsilon_{0}[\% o]$ & 0.10 & Model Code 2010 \\
\hline & & Average strain $\varepsilon_{1}[\% o]$ & 0.15 & Model Code 2010 \\
\hline & & Average strain $\varepsilon_{2}[\% o]$ & 0.27 & Model Code 2010 \\
\hline & & Average strain $\varepsilon_{3}[\% o]$ & 20.00 & Model Code 2010 \\
\hline \multirow[t]{10}{*}{ Models M + L } & \multirow[t]{10}{*}{ SFRC slab } & Average compressive strength [MPa] & 46.73 & UNE 83507:2004 \\
\hline & & Average modulus of elasticity [GPa] & 29.03 & UNE 83316:1996 \\
\hline & & Average stress $\sigma_{0}[\mathrm{MPa}]$ & 3.09 & Model Code 2010 \\
\hline & & Average tensile stress $\sigma_{1}$ [MPa] & 3.43 & Model Code 2010 \\
\hline & & Average residual stress $\sigma_{2}[\mathrm{MPa}]$ & 2.44 & Model Code 2010 \\
\hline & & Average residual stress $\sigma_{3}$ [MPa] & 2.43 & Model Code 2010 \\
\hline & & Average strain $\varepsilon_{0}[\% o]$ & 0.11 & Model Code 2010 \\
\hline & & Average strain $\varepsilon_{1}[\% o]$ & 0.15 & Model Code 2010 \\
\hline & & Average strain $\varepsilon_{2}[\% o]$ & 0.27 & Model Code 2010 \\
\hline & & Average strain $\varepsilon_{3}[\% o]$ & 20.00 & Model Code 2010 \\
\hline
\end{tabular}




\section{Conclusions}

An extensive experimental program and several numerical analyses were performed in the present study regarding the behaviour of slabs reinforced solely with steel fibres. The following conclusions may be derived from the study.

- The geometry of the slabs has a significant influence on the flexural behaviour and in the stress redistribution capacity. In fact, the slabs $S$ are strongly affected by the geometry and transfer load almost exclusively in the shortest direction. On the average, they exhibit $7.0 \%$ and $16.3 \%$ higher maximum loads than that of slabs $M$ and $L$, respectively. These differences indicate that the residual strength and the ductility provided by the fibres allow the bigger slabs to reach load levels close to the smaller ones.

- The slabs produced in the experimental program are subjected to an extensional flow. The latter makes fibres rotate and align perpendicular to the streamlines, which is in accordance with previous studies from the literature.

- A fibre orientation pattern was proposed based on the fibre orientation measured with the inductive method in the slabs and in the beams used in the bending test. A more favourable fibre orientation with the cracking plane was observed in the beams due to the restricted concrete flow and the influence of the walleffect. This suggests that an enhanced response at a section level should be expected in the beam in comparison with the slab. If so, the direct application of the constitutive model obtained in the beam test could lead to an overestimation of the response of the slabs.

- The numerical simulations performed in this study confirmed such hypothesis, revealing that the direct use of the constitutive equation from the small-scale specimens may lead to unsafe predictions of the structural behaviour of real-scale elements. This reinforces the need to consider the orientation factor $(K)$ introduced by the Model Code 2010.

- Values of $K$ ranging from 2.0 and 3.2 were estimated through a numerical fit of parameters and through a simplified approach based on the fibre distribution assessed with the inductive method. Both approaches provided curves that fit the experimental results. This suggests that the predicted fibre distribution may be used as an indirect parameter to assess the orientation factor $K$ in a simplified way, even before the element is produced.

- Despite the good results obtained, the curves of Fig. 11 reveal that the use of the same $K$ for $\sigma_{2}$ and $\sigma_{3}$ leads to a fit that is better for one part of the curve than for the other. This differential fit suggests that it may be appropriate to modify the original philosophy included in the Model Code 2010. To achieve a good fit in the whole extent of the curves, it might be necessary to define different values of $K$ for $\sigma_{2}$ and $\sigma_{3}$ or to affect other parameters of the constitutive model, such as $\sigma_{1}$. Additional research should be conducted to obtain a bigger database of experimental results to analyse this issue.

\section{Acknowledgements}

The authors of this document wish to show their gratitude for the economic support received through the Research Project BIA2010-17478: Construction processes by means of fibre reinforced concretes. The authors thank the company ESCOFET S.A. for their collaboration in the development of the experimental program. The first and second authors acknowledge the grant FI provided by the Comissionat per a Universitats del DIUE de la Generalitat de Catalunya i del Fons Social Europeu and the Grant FPI-UPC provided by the UPC, respectively. The first and second authors also acknowledge the support of the Col-legi d'Enginyers de Camins, Canals i Ports de Catalunya. The authors express their gratitude to Assitant Prof. Dr. Steffen Grünewald for his helpful comments and reviews on the manuscript.

\section{References}

[1] Grünewald S, Laranjeira F, Walraven J, Aguado A, Molins C. Improved tensile performance with fiber reinforced self-compacting concrete. In: ParraMontesinos, Reinhardt, Naaman, editors. Proceedings of the 6th international workshop on high performance fiber reinforced cement composites (HPFRCC 6), Ann Arbor, Michigan; June 20-22, 2011.

[2] Ferrara L, Ozyurt N, di Prisco M. High mechanical performance of fibre reinforced cementitious composites: the role of "casting-flow induced" fibre orientation. Mater Struct 2011;44:109-28.

[3] Stähli P, Custer R, van Mier JGM. On flow properties, fibre distribution, fibre orientation and flexural behaviour of FRC. Mater Struct 2008:41:189-96.

[4] Barnett S, Lataste J-F, Parry T, Millard S, Soutsos M. Assessment of fibre orientation in ultra high performance fibre reinforced concrete and its effect on flexural strength. Mater Struct 2010;43(7):1009-23.

[5] Wille K, Parra-Montesinos GJ. Effect of beam size, casting method and support conditions on flexural behavior of ultra-high-performance fiber-reinforced concrete. ACI Mater J 2012;109(3):379-88.

[6] fib (2010) Model Code 2010. International Federation for Structural Concrete, Lausanne.

[7] Blanco A, Cavalaro S, de la Fuente A, Grünewald S, Blom CBM, Walraven JC. Application of FRC constitutive models to the modelling of slabs. Minor Rev Mater Struct 2014

[8] Grünewald S. Performance-based design of self-compacting fibre reinforced concrete. Doctoral Thesis, Delft University of Technology, Delft; 2004.

[9] Gettu R, Gardner D, Saldivar H, Barragán B. Study of the distribution and orientation of fibers in SFRC specimens. Mater Struct 2005;38(1):31-7.

[10] Laranjeira F. Design-oriented constitutive model for steel fiber reinforced concrete. Doctoral Thesis, Universitat Politècnica de Catalunya-BarcelonaTech, Barcelona; 2010.

[11] di Prisco M, Ferrara L, Caverzan A. Self-compacting fibre reinforced concrete: is the material really isotropic? In: $3^{\circ}$ Congreso Iberoamericano sobre hormigón autocompactante: Avances y Oportunidades, Madrid, España; 2012. p. 17-31.

[12] AENOR. UNE 83507:2004. Hormigones con fibras. Rotura por compresión. Asociación Española de Normalización y Certificación, Madrid; 2004 [in Spanish].

[13] AENOR. UNE 83316:1996. Ensayos de hormigón. Determinación del módulo de elasticidad en compresión., Asociación Española de Normalización y Certificación, Madrid; 1996 [in Spanish].

[14] CEN. EN 14651:2005. Test method for metallic fibrered concrete - measuring the flexural tensile strength (limit of proportionality (LOP), residual). European Committee for Standardization, Brussels; 2005.

[15] Parmentier B, De Grove E, Vandewalle L, Van Rickstal F. Dispersion of the mechanical properties of FRC investigated by different bending tests. In: Stoelhost Walraven, editor. Fib symposium "Tailor Made Concrete Structures". Amsterdam: Taylor \& Francis Group; 2008. p. 507-12.

[16] Molins C, Aguado A, Saludes S. Double punch test to control the energy dissipation in tension of FRC (Barcelona test). Mater Struct 2009;42(4): 415-25.

[17] Juan-García P. Evaluación no destructiva de estructuras de obra civil mediante métodos electromagnéticos. Doctoral Thesis, Universitat Politècnica de Catalunya-BarcelonaTech, Barcelona; 2011 [in Spanish].

[18] Torrents J, Blanco A, Pujadas P, Aguado A, Juan-García P, Sánchez-Moragues M. Inductive method for assessing the amount and orientation of steel fibers in concrete. Mater Struct 2012;45(10):1-16.

[19] Cavalaro S, López R, Torrents JM, Aguado A. Improved assessment of fibre content and orientation with inductive method in SFRC. Mater Struct 2014. http://dx.doi.org/10.1617/s11527-014-0279-6.

[20] Maturana A, Sanchez R, Canales J, Orbe A, Ansola R, Veguería E. Technical economic analysis of steel fibre reinforced concrete flag slabs. A real building application. XXXVII IAHSWorld Congress on Housing: 2010.

[21] Orbe A, Cuadrado J, Losada R, Rojí E. Framework for the design and analysis of steel fibre reinforced self-compacting concrete structures. Constr Build Mater 2012:35:676-86.

[22] Orbe A, Rojí E, Losada R, Cuadrado J. Calibration patterns for predicting residual strengths of steel fibre reinforced concrete (SFRC). Composites Part B 2014;58:408-17.

[23] Galeote E. Correlación entre el ensayo a flexotracción y el ensayo multidireccional para el HRF. Master Thesis, Universitat Politècnica de Catalunya-BarcelonaTech, Barcelona; 2014 [in Spanish].

[24] Johansen KW. Yield-line theory. London: Cement and Concrete Association; 1962.

[25] Kameswara RCVS. Effectiveness of random fibres in composites. Cem Concr Res 1979;9:685-93.

[26] Dupont D. Modelling and experimental validation of the constitutive law $(\sigma-\varepsilon)$ and cracking behaviour of steel fibre reinforced concrete. Ph.D. Thesis, Catholic University of Leuven, Leuven; 2003. 
[27] Dupont D, Vandewalle L. Distribution of steel fibers in rectangular sections. Cem Concr Compos 2004;27:391-8.

[28] Boulekbache B, Hamrat M, Chemrouk M, Amziane S. Flowability of fibrereinforced concrete and its effect on the mechanical properties of the material. Constr Build Mater 2010;24(9):1664-71.

[29] Cervenka V. Simulating a response. Concr Eng Int 2000;4(4):45-9.

[30] de Montaignac R, Massicotte B, Charron J-P, Nour A. Design of SFRC structural elements: flexural behavior prediction. Mater Struct 2012:45(4): $623-36$.
[31] Kooiman AG. Modelling steel fibre reinforced concrete for structural design. Doctoral Thesis, Delft University of Technology, Delft; 2000.

[32] Pedersen C. New production processes. Materials and calculation techniques for fibre reinforced pipes. Doctoral Thesis, Technical University of Denmark, Kongens Lyngby; 1996.

[33] CEN. EN1337-3:2005 Structural bearings - Part 3: Elastomeric bearings. European Committee for Standardization, Brussels; 2005

[34] Krenchel H. Fibre spacing and specific fibre surface. In: Neville A, editor. Fibre reinforced cement and concrete. UK: The Construction Press; 1975. p. 69-79. 